\title{
Breastfeeding in Saudi Arabia: a review
}

Daifellah A M Al Juaid', Colin W Binns² and Roslyn C Giglia ${ }^{3^{*}}$

\begin{abstract}
Background: Breastfeeding is viewed as the optimal method of infant feeding that provides many benefits to both the infant and the mother. The monitoring and reporting of breastfeeding indicators are essential for any country to plan and implement effective promotion programs for sustainable breastfeeding. The aim of this review is to examine the available studies and data on breastfeeding in Saudi Arabia, and determine the potential factors that affect breastfeeding practices and duration in this country.

Methods: The databases of Web of Knowledge, Science Direct and PubMed were searched using the relevant key words. Only studies that reported breastfeeding practices, rates and indicators in Saudi Arabia were included. Standard WHO definitions for breastfeeding categories were used in this review.

Results: Seventeen cross-sectional studies were identified and reviewed and five stated they used standard definitions. The self-administered questionnaire as a measurement tool was the predominant method of data collection. Infants' ages range from less than six months up to five years. Initiation rates were high (mostly above $90 \%$ ), but a few studies reported low rates of timely initiation (within the first hour). The exclusive breastfeeding rate could not be accurately determined as rates range from $0.8 \%$ to $43.9 \%$ among studies due to the lack of clear definitions and the nature of study design. The partial (mixed) feeding method was common and the category of 'any breastfeeding' has generally high rates. The mean duration of breastfeeding has showed a progressive decline over time from 13.4 months in 1987 to 8.5 months in 2010. Factors associated with a high prevalence of breastfeeding and longer duration include increased maternal age, low educational levels, rural residence, low income, multiparity and avoiding contraceptives. The most common reason for breastfeeding cessation was insufficient breast milk. Other reasons include sickness, new pregnancy and breastfeeding problems.

Conclusions: Breastfeeding indicators in Saudi Arabia could not be monitored or compared relying on the available data because no longitudinal studies have been conducted in this country. A cohort study design would be the most appropriate procedure to rigorously assess and report valid results on breastfeeding practices and patterns in the Saudi society.
\end{abstract}

Keywords: Breastfeeding, Breastfeeding duration, Epidemiology, Infant feeding, Saudi

\section{Background}

Breastfeeding is the optimal method of infant feeding bringing short- and long-term benefits for infants, mothers, environment, economy and the entire society [1-3]. The World Health Organization (WHO) and other international health bodies have recommended exclusive breastfeeding for six months after birth [4-6]. It is also recommended that breastfeeding continues for two years or longer together with nutritionally-adequate complementary foods $[2,3]$.

\footnotetext{
* Correspondence: r.giglia@exchange.curtin.edu.au

${ }^{3}$ School of Public Health, WA Centre for Health Promotion Research, Curtin University, Perth, Western Australia 6845, Australia

Full list of author information is available at the end of the article
}

The Eastern Mediterranean Regional Office of WHO (EMRO) has reported high rates $(>60 \%)$ of early breastfeeding initiation with $60 \%$ of mothers continuing to breastfeed to 12 months in the Middle East and North Africa (MENA) countries [7]. Despite these recent reports of high rates, previously low rates of exclusive breastfeeding had been reported from this region where only $40 \%$ or less of infants under six months were being exclusively breastfed [7]. Dop and Benbouzid [8] reported that the mean rate of 'exclusive breastfeeding' at four months in the Middle East region is $24 \%$, including Lebanon (7\%), Yemen (15\%), Pakistan (16\%), Jordan (32\%) and Iran (48\%). The Global Data Bank on infant and young child feeding (updated in 2009) contained

\section{() Biomed Central}


low 'exclusive breastfeeding' rates from the MENA region. These low rates have been observed in countries such as Algeria (10.4\% at four months and $6.9 \%$ at six months), Sudan (21.4\% at four months and $15.6 \%$ at six months) and Egypt (30.3\% at six months) [9].

The Kingdom of Saudi Arabia (KSA) has a population of 27 million and an area of two million square kilometers [10]. About one quarter (24.8\%) of the population live in Riyadh, the capital city of KSA, the Western region (Jeddah, Makkah and Taif) is inhabited by another 24\%; the Eastern Province by $13.3 \%$ and the remaining spread over the rest of the country [10]. Saudi Arabia is a high-income country and the government spends $6.5 \%$ of the national income on health, with USD 345 of health expenditure per capita in 2010 [11]. Life expectancy is 69 years for males and 75 years for females [12].

There is insufficient data available on breastfeeding in Saudi Arabia to monitor progress and develop promotion programs. The World Health Organization does not report any breastfeeding data in the country profile because there are no national data on breastfeeding $[11,13]$. A previous review on breastfeeding in Saudi Arabia (2003) documented the deficiencies in statistics with incomplete and inconsistent official data and the lack of uniformity in research on breastfeeding [14]. Because of the public health and clinical significance of breastfeeding, after a decade it is appropriate to further review the data that are available.

The objective of this review is to provide a summary of breastfeeding patterns, practices, rates and duration in Saudi Arabia from the published literature. The review will also include an outline of factors associated with breastfeeding practices as well as reasons for the discontinuation of breastfeeding in the KSA.

\section{Methods}

All reported studies on breastfeeding in Saudi Arabia that have been published in the English language until present were sourced. A literature search was undertaken using the Web of Knowledge, Science Direct and PubMed databases. These databases were searched using the key words: Saudi, breastfeeding, breast-feeding, breastfeeding and infant feeding. Where the study appeared to be relevant by including information on the breastfeeding practices in KSA and to document rates and duration, the full text was obtained. The reference lists from obtained full texts were used as additional sources to identify additional relevant studies. Papers concerning knowledge, beliefs and attitudes of women towards breastfeeding were excluded if they did not report the actual practices and rates. Also, studies that investigated related issues such as birth interval, unilateral breastfeeding and caesarean section where breastfeeding was only a secondary associated factor were excluded.
The PRISMA diagram in Figure 1 shows the process of selecting studies that were included in this review [15]. The following definitions, which are adopted by the WHO, are used in this review $[16,17]$. Where a paper claimed to be reporting exclusive breastfeeding, but did not conform to the WHO definition of exclusive breastfeeding it was given the most appropriate classification.

'Exclusive breastfeeding': allows the infant to receive breast milk only, with no other liquids or foods, not even water, except drops of syrups, vitamins, minerals or medicines.

'Predominant breastfeeding': allows the infant to receive mixed feeding of breast milk and other liquids, solid or semi-solid foods.

'Any breastfeeding': allows the infant to receive breast milk (including milk expressed or from a wet nurse) with any foods or liquid, including non-human milk or formula.

When a study used the mere term "breastfeeding" without classifying infants to the above-mentioned categories, it was dealt with under 'any breastfeeding' definition in this review.

The values of the mean breastfeeding duration that were reported in the studies were entered to Microsoft Excel $^{\circledR}$ version 2010 to generate a graph and linear regression equation (Figure 2) illustrating the trend of breastfeeding duration over years. There were only seven studies that reported mean breastfeeding duration [18-24]. The seven means of breastfeeding duration were entered to Microsoft Excel $^{\circledR}$ as values of Y-axis, and the years of the seven studies were entered as values of $\mathrm{X}$-axis. Using the features in the Microsoft Excel ${ }^{\circ}$, a scatter plot was generated and a linear model was fitted to demonstrate the trend in the breastfeeding duration over time (Figure 2).

All studies included in this review have been assessed against the National Health and Medical Research Council (NHMRC) levels of evidence and ranked according to their designs [25]. NHMRC levels of evidence range from I, the strongest to IV, which is the weakest [25].

\section{Results}

\section{Breastfeeding definitions and measurement}

The search revealed 17 studies, which met the inclusion criteria, and Table 1 provides information on the definitions of breastfeeding categories they used and levels of evidence they provide. Only five of studies stated that they used the WHO definitions for breastfeeding categories in their methodology sections [21,22,26-28]. Studies that have not used standard definitions might misclassify infants into incorrect breastfeeding categories, thus the initiation rates, breastfeeding rates (particularly exclusive breastfeeding rates) and breastfeeding duration may be overestimated [17]. 


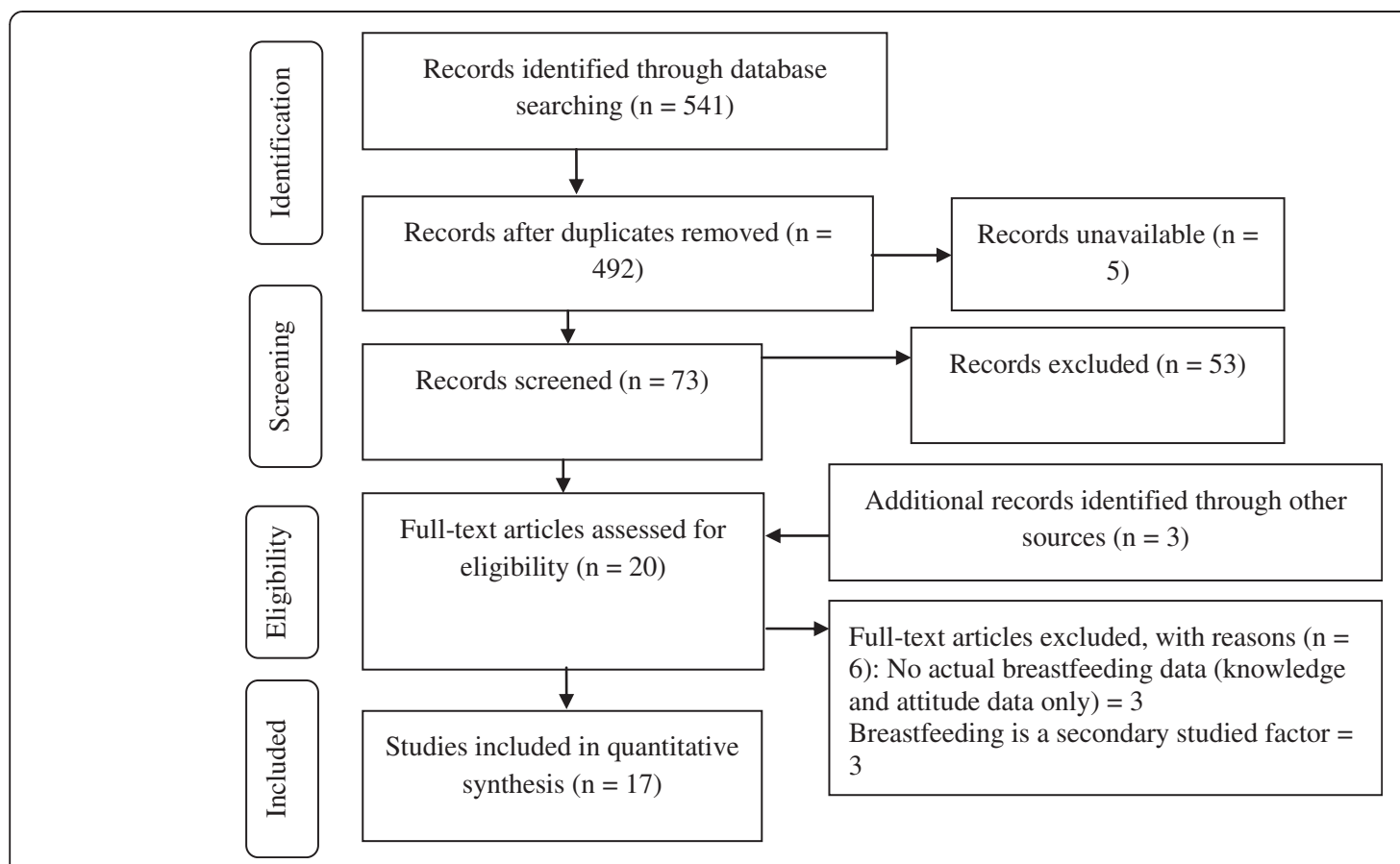

Figure 1 Process of selecting the studies included in this review.

Samples were often recruited during visits to primary health care centres (PHCCs) for vaccination or during home visits. Almost all studies used self-administered questionnaires to report and measure breastfeeding practices from participating mothers. These questionnaires collected data on socio-demographic variables, breastfeeding patterns and practices, infant attributes, and reasons for breastfeeding cessation. Some data, including delivery mode and birth weight were collected from health records of mothers and infants at hospitals and PHCCs. All of these studies were cross-sectional, and data were usually collected relying on mothers' memory, with the possibility of recall bias. The age range of infants included in the studies (and hence length of recall) varied across a wide range of ages. Four studies [18-20,29] asked mothers about feeding their infants in the last five years, four studies $[21,23,24,27]$ included infants less than 2.5 years, and five studies investigated feeding practices in infants aged less than 12 months [30-34]. Three studies $[22,26,28]$ included infants 6 months or younger, while one study included infants and children 0-9 years old [35]. No prospective cohort studies have been published.

\section{Breastfeeding rates}

Breastfeeding initiation, 'exclusive' and 'any breastfeeding' rates at selected age ranges and the mean duration as reported in these studies along with times, sites and sample sizes used in the studies are summarised in Table 2. Initiation rates were above $90 \%$ in almost all of the identified studies. One study found a considerable difference between urban and rural communities in

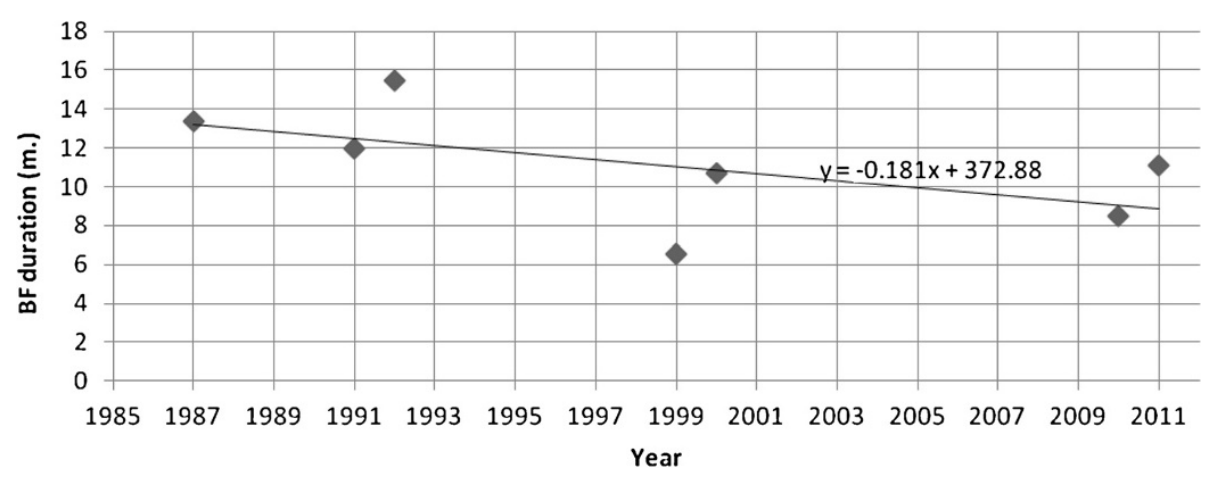

Figure 2 The decline in breastfeeding duration in Saudi Arabia since 1985, derived from identified studies. 
Table 1 Definitions and categorisation of infants as reported in the identified studies

\begin{tabular}{|c|c|c|}
\hline Study & Definitions - infant feeding categories & $\begin{array}{l}\text { NHMRC } \\
\text { level [25] }\end{array}$ \\
\hline Serenius, 1988 [29] & No definitions provided & IV \\
\hline $\begin{array}{l}\text { Al-Othaimeen, } 1987 \\
\text { [35] }\end{array}$ & No definitions provided & IV \\
\hline $\begin{array}{l}\text { Al-Mazrou, } 1994[18], \\
\text { p. } 267\end{array}$ & $\begin{array}{l}\text { "The term weaning was used to denote the event of stopping of breastfeeding. Supplementation meant the } \\
\text { addition of other milks or semi-solids to a breastfed baby". }\end{array}$ & IV \\
\hline Madani, 1994 [30] & No definitions provided & IV \\
\hline $\begin{array}{l}\text { Al-Shehri, } 1995[20] \text {, } \\
\text { p. } 41\end{array}$ & $\begin{array}{l}\text { "Breastfeeding only refers to those infants who were breastfed exclusively without any reconstituted powdered } \\
\text { milk or any other infant formula. Bottlefed refers to the infants and children who were given reconstituted } \\
\text { powdered milk or other infant formula". }\end{array}$ & IV \\
\hline Kordy, 1992 [24] & No definitions provided & IV \\
\hline $\begin{array}{l}\text { Shawky, } 2003[31], \\
\text { p. } 92\end{array}$ & $\begin{array}{l}\text { "If the mother lactated only or breast fed together with bottle or solid foods, breast feeding was considered to be } \\
\text { still continuing". }\end{array}$ & IV \\
\hline $\begin{array}{l}\text { Al-Ayed, } 1998 \text { [32], } \\
\text { p. } 114\end{array}$ & $\begin{array}{l}\text { "Infants were grouped into the following broad categories for analysis: exclusively breastfed (breast + semisolids); } \\
\text { exclusively bottle fed (bottle + semisolids), and infants on mixed feeding (breast + bottle + semisolids)". }\end{array}$ & IV \\
\hline Al-Jassir, 2004 [19] & No definitions provided & IV \\
\hline Khattab, 2000 [23] & No definitions provided & IV \\
\hline Fida, 2003 [33] & No definitions provided & IV \\
\hline Al-Jassir, 2006 [34] & No definitions provided & IV \\
\hline $\begin{array}{l}\text { El Mouzan, } 2009[27], \\
\text { p. } 21\end{array}$ & $\begin{array}{l}\text { "According to the WHO definition, exclusive breastfeeding means no other food or fluids (including plain water } \\
\text { and juices). Infant milk formulas are considered complementary food". }\end{array}$ & IV \\
\hline $\begin{array}{l}\text { Al-Hreashy, } 2008 \text { [26], } \\
\text { p. } 428\end{array}$ & "The WHO definitions for breastfeeding were adopted for classification of infant feeding patterns". & IV \\
\hline $\begin{array}{l}\text { El-Gilany, } 2011[28], \\
\text { p. } 209\end{array}$ & $\begin{array}{l}\text { "According to the World Health Organization definition, exclusive breastfeeding means no other food or fluids } \\
\text { (including plain water and juices), and the infant consumes human milk with no supplements of any type except } \\
\text { for vitamins, minerals, and medications". }\end{array}$ & IV \\
\hline $\begin{array}{l}\text { Amin, } 2011[21], \\
\text { p. } 60\end{array}$ & $\begin{array}{l}\text { "Breastfeeding definitions used in this study were according to the infant feeding recommendations of the } 2001 \\
\text { WHO Expert Consultation and the 55th World Health Assembly". }\end{array}$ & IV \\
\hline $\begin{array}{l}\text { Eldeek, } 2012[22], \\
\text { p. } 157\end{array}$ & "World Health Organization (WHO) definitions were used for classification of infants' nutrition patterns". & IV \\
\hline
\end{tabular}

initiation rates $(90 \%$ for rural versus $76 \%$ for urban groups) [29]. In time to initiation of breastfeeding, El-Gilany et al. [28] reported that only $11.4 \%$ of mothers started breastfeeding within the first hour after delivery while Amin et al. [21] found that 77.8\% of studied mothers had initiated breastfeeding within 24 hours postpartum.

Because the vast majority of identified studies were of cross-sectional design and did not provide a standard definition for 'exclusive breastfeeding', the rate of 'exclusive breastfeeding' in Saudi Arabia could not be determined. However, those studies which used the WHO definition reported that the 'exclusive breastfeeding' rate at six months of age ranged from $1.7 \%$ [26] to $24.4 \%$ [28]. Other studies found low rates of 'exclusive breastfeeding' at six months after birth: 0.8\% [19]; 8.9\% [24] and $5.6 \%$ [35]. On the other hand, two national surveys recorded relatively high rates of 'exclusive breastfeeding' at six months of age of $33 \%$ and $38 \%$, respectively $[18,20]$. Also, two other studies found that this rate was
$37 \%$ in children under 24 months [30], and $43.9 \%$ in infants less than 12 months of age [23]. Therefore, the prevalence of 'exclusive breastfeeding' in the KSA is inconsistently reported and comparisons with the WHO and other international organisations' recommendations cannot be made because of the weakness of study design used in these investigations.

Mixed (partial) feeding (breastfeeding combined with bottle feeding) has been very common among the Saudi mothers compared to other feeding methods as reported in many of the studies [14,34]. For instance, AlOthaimeen et al. [35] documented that 57.9\% of infants and children under 18 months had received breastfeeding along with artificial infant formula by bottle and glass while only $21.5 \%$ and $20.6 \%$ of these subjects were exclusively breastfed or bottle-fed, respectively. The 'mixed breastfeeding' rates reported by other studies were $88.6 \%$ at birth [27], $49.8 \%$ at six months after birth [21] and $56 \%$ of all infants and children less than two years old [18]. 
Table 2 Results of studies that have investigated breastfeeding in Saudi Arabia

\begin{tabular}{|c|c|c|c|c|c|c|c|c|c|}
\hline & \multirow[t]{2}{*}{ Study year \& location } & \multirow[t]{2}{*}{ Study design } & \multirow{2}{*}{$\begin{array}{l}\text { Sample } \\
\text { size }(n)\end{array}$} & \multirow{2}{*}{$\begin{array}{l}\text { Initiation } \\
\text { rate }(\%)\end{array}$} & \multirow[t]{2}{*}{ Child age $\left(\mathrm{m}^{\dagger}\right)$} & \multirow{2}{*}{$\begin{array}{l}\text { Exclusive } \\
\text { BF }^{*}(\%)\end{array}$} & \multirow{2}{*}{$\begin{array}{l}\text { Child } \\
\text { age }\left(\mathrm{m}^{\dagger}\right)\end{array}$} & Any BF ${ }^{*}(\%)$ & \multirow{2}{*}{$\begin{array}{l}\mathrm{BF}^{*} \\
\text { duration }\left(\mathrm{m}^{\dagger}\right.\end{array}$} \\
\hline & & & & & & & & $\mathrm{U}^{* *}$ & \\
\hline \multirow[t]{3}{*}{1} & \multirow{3}{*}{$\begin{array}{l}\text { 1979-81, Central \& South-West } \\
\text { KSA (Serenius } 1988 \text { [29]) }\end{array}$} & \multirow[t]{3}{*}{ Cross-sectional } & \multirow[t]{3}{*}{2196} & $90 \quad R^{* *}$ & \multirow[t]{3}{*}{-} & & 1 & 90 & Median= \\
\hline & & & & $76 U^{* *}$ & & & 3 & 90 & $17.8 R^{* *}$ \\
\hline & & & & & & & 6 & 85 & $2.1 U^{* *}$ \\
\hline \multirow[t]{3}{*}{2} & \multirow{3}{*}{$\begin{array}{l}\text { 1987, National } \\
\text { (Al-Othaimeen } 1987 \text { [35]) }\end{array}$} & \multirow[t]{3}{*}{ Cross-sectional } & \multirow[t]{3}{*}{767} & \multirow[t]{3}{*}{89.9} & $<6$ & 4.4 & & 29 & \multirow[t]{3}{*}{ - } \\
\hline & & & & & $6-$ & 5.6 & & 15 & \\
\hline & & & & & $12-$ & 9.1 & & 11 & \\
\hline \multirow[t]{3}{*}{3} & \multirow{3}{*}{$\begin{array}{l}\text { 1987, National } \\
\text { (Al-Mazrou } 1994 \text { [18]) }\end{array}$} & \multirow[t]{3}{*}{ Cross-sectional } & \multirow[t]{3}{*}{6086} & \multirow[t]{3}{*}{90.1} & 1 & 55 & & 95 & Mean $=13.4$ \\
\hline & & & & & 3 & 36 & & 92 & $14.4 R^{* *}$ \\
\hline & & & & & 6 & 33 & & 88 & $12.3 U^{* *}$ \\
\hline 4 & $\begin{array}{l}\text { 1990, Taif (West) } \\
\text { (Madani } 1994 \text { [30]) }\end{array}$ & Cross-sectional & 1019 & 98 & $\leq 12$ & 43.9 & & 56.1 & - \\
\hline 5 & 1991, National & Cross-sectional & 6308 & 93 & $<5$ & 53 & & 87 & Mean $=$ \\
\hline & & & & & $6-12$ & 38 & & 67 & $13 R^{* *}$ \\
\hline & & & & & $12+$ & 18 & & 24 & $11 U^{* *}$ \\
\hline 6 & 1992, Makkah (West) & Cross-sectional & 476 & 97.1 & $<36$ & 8.9 & & 42.4 & Mean $=$ \\
\hline & & & & & & & & & $14.61 \pm 3.53$ \\
\hline 7 & $\begin{array}{l}\text { 1997, Jeddah (West) } \\
\text { (Shawky } 2003 \text { [31]) }\end{array}$ & Cross-sectional & 400 & 94 & - & & 6 & 54 & Median $=6$ \\
\hline 8 & $\begin{array}{l}\text { 1995, Riyadh (Central) } \\
\text { (Al-Ayed } 1998 \text { [32]) }\end{array}$ & Cross-sectional & 347 & - & 6 & 22.1 & & 51.6 & - \\
\hline 9 & 1999, Riyadh (Central) & Cross-sectional & 21507 & 98.9 & $4-6$ & 0.8 & 6 & 34.3 & Mean $=$ \\
\hline & (Al-Jassir 2004 [19]) & & & & & & & & $6.57 \pm 5.71$ \\
\hline 10 & 2000, Abha (South-West) & Cross-sectional & 100 & - & $<24$ & 37 & & 47 & Mean $=$ \\
\hline & & & & & & & & & $10.7 \pm 6.9$ \\
\hline 11 & $\begin{array}{l}\text { 2001-02, Jeddah (West) } \\
\text { (Fida } 2003 \text { [33]) }\end{array}$ & Cross-sectional & 128 & 95 & - & & $\leq 12$ & 82.8 & - \\
\hline 12 & $\begin{array}{l}\text { 2002-03, National } \\
\text { (Al-Jassir } 2006 \text { [34]) }\end{array}$ & Cross-sectional & 4872 & 91.9 & 3 & 23.9 & $4-6$ & 50 & - \\
\hline 13 & 2004-05, National & Cross-sectional & 5339 & 91.6 & Birth & 70.8 & & 88.8 & - \\
\hline & & & & & 1 & 39 & & 49 & \\
\hline & & & & & 4 & 16.4 & & 20.5 & \\
\hline & & & & & 6 & 8 & & 10.2 & \\
\hline 14 & $\begin{array}{l}\text { 2005, Riyadh (Central) } \\
\text { (Al-Hreashy } 2008 \text { [26]) }\end{array}$ & Cross-sectional & 578 & 95 & 6 & 1.7 & & 94.3 & - \\
\hline 15 & $\begin{array}{l}\text { 2009, AlHassa (Eastern) } \\
\text { (El-Gilany } 2011 \text { [28]) }\end{array}$ & Cross-sectional & 1904 & 91.9 & 6 & 24.4 & - & & - \\
\hline 16 & 2010, AlHassa (Eastern) & Cross-sectional & 641 & 91 & Birth & 66.5 & & 77.8 & Mean= \\
\hline & & & & & 2 & 32.9 & & 76 & $8.5 \pm 7.4$ \\
\hline & & & & & 4 & 19.2 & & 67 & Median= \\
\hline & & & & & 6 & 12.2 & & 61 & 6 \\
\hline 17 & 2011, Jeddah (West) & Cross-sectional & 600 & & $\leq 6$ & 25 & & 58 & Mean $=$ \\
\hline & $(E$ & & & & & & & & $11.1 \pm 6.64$ \\
\hline
\end{tabular}


However, Al-Shehri et al. [20] found that $44 \%$ of studied infants and children (under five years, $\mathrm{n}=4773$ ) were bottle-fed only and $28 \%$ were breastfed only whereas only $16 \%$ of them were on breast and bottle together and $12 \%$ were weaned.

In this review, despite the deficiencies in study design, most of the studies documented high rates of 'any breastfeeding' (Table 2). In a recent national survey, El Mouzan et al. [27] reported a rate of only $10.2 \%$ for 'any breastfeeding' and $8 \%$ for 'exclusive breastfeeding' among infants aged six months. In contrast, another recent study conducted in the central region (Riyadh) stated that the corresponding rates were $94.3 \%$ and $1.7 \%$, respectively [26].

This significant variation in results is an illustration of the inconsistent findings resulting from the absence of appropriate study design, including length of recall, sample size and selection.

Breastfeeding duration appears to have declined over the past 25 years. Although the graph of the 'mean breastfeeding duration' based on the seven studies that calculated it [18-24] does not show a perfect linear regression, there is a declining trend in the 'mean breastfeeding duration' over time (Figure 2). While the 'mean breastfeeding duration' was as high as 13.4 months in 1987, it has dropped to only 6.8 months in 1999 and 8.5 months in 2010 (Table 2 and Figure 2). These findings, however, can be considered only indicative because of the variation in the study samples and locations between included studies.

\section{Factors associated with breastfeeding practices Maternal age}

Fifteen studies examined the effects of maternal age on breastfeeding practices and duration. Just over half of these studies (eight papers) concluded that the prevalence of breastfeeding was higher with longer duration among older mothers compared to their younger counterparts [18,20,21,23,24,29,34,35]. Results from a recent study revealed that increased maternal age was significantly associated with early initiation of breastfeeding (within 24 hours of delivery) (odds ratio $[\mathrm{OR}]=2.24$, $95 \%$ confidence interval $[\mathrm{CI}]=1.37-3.68, p$-value $=0.016$; with longer duration $(p$-value $=0.001)$ and with exclusivity of breastfeeding $(\mathrm{OR}=1.14,95 \% \mathrm{CI}=1.03-1.23, p$-value $=$ 0.034 ) [21]. In a national survey, Al-Jassir et al. [34] concluded that younger mothers tended to introduce solid foods within the first two months, earlier than older mothers $(p \leq 0.05)$. In contrast, six studies found that the effects of maternal age on breastfeeding were not statistically significant [26,28,30-33]. One study found that the mean age of mothers who practiced 'exclusive breastfeeding' was $23.4 \pm 4.46$ years; which was younger than the mean age of those who adopted artificial feeding (29.71 \pm 7.89 years) [22].

\section{Mother's education and employment}

Education and consequent employment were not common among Saudi women until recently, as old studies reported that the vast majority of subjects were illiterate and non-workers (housewives). For example, Madani et al. [30] found that the proportions of mothers in their sample who were illiterate and not working were $80 \%$ and $96.2 \%$, respectively. This trend has changed over time and levels of education and employment have increased due to rapid advancements in economy, education and other social aspects of life in the KSA. In a recent study (2012), it was found that $67 \%$ of studied mothers were working and about $91 \%$ have had at least intermediate schooling [22].

Four studies concluded that working mothers breastfed less frequently and had shorter duration than nonworkers, and that these differences were statistically significant [21,26,28,32]. A further five studies found that working status had no significant effect on breastfeeding practices and duration [23,24,30,31,33], and one study reported a higher 'exclusive breastfeeding' rate among working mothers compared to non-working mothers $(p=0.005)$ [22].

Generally, higher levels of education were associated with less breastfeeding, particularly with 'exclusive breastfeeding' and a shorter duration of 'any breastfeeding' [18-21,24,26,28,30,34,35]. Results from three other studies reported that education has no significant effect on breastfeeding status and duration [23,32,33]. However, sample sizes in these three studies were very small (see Table 2), and thus, their results might be underpowered.

\section{Family income and type of residence}

Five studies investigated the disparities in breastfeeding practices between rural and urban communities $[18,20,21,28,29]$. All agreed that breastfeeding was more prevalent among rural mothers with longer duration and later introduction of supplements than urban mothers. These differences in favour of rural areas were statistically significant in three of the five studies. It is worth noting that the majority of rural women in the KSA tend to be illiterate or have a lower level of education compared to their urban counterparts $[21,24]$. This could support the hypothesis that there might be an association between the level of maternal education and belonging to a rural community, resulting in better breastfeeding practices. Family income was examined by four studies: two of them found no significant association between income and breastfeeding [28,33]. The 
other two highlighted a decline in breastfeeding with high income $[21,32]$.

\section{Other factors}

Other factors associated with breastfeeding that have been studied in the KSA include parity, oral contraceptive use and caesarean section. Parity was examined by eight studies. Four found that multi-parity was correlated with a longer duration and higher prevalence of breastfeeding [21,23,26,32]. For example, Al-Hreashy et al. [26] concluded that primiparous mothers have a shorter duration and more likely to introduce artificial formula in the first six months of life compared to mothers of two to four children or those who have more than five children $(\mathrm{OR}=0.36,95 \% \mathrm{CI}=0.21-0.64$ and $\mathrm{OR}=0.18,95 \% \mathrm{CI}=0.09-0.35$; respectively, with primiparous mothers being the reference group). The other three studies did not find any significant association between parity and breastfeeding practices and duration $[28,31,33]$. Furthermore, in a study conducted in a rural area in Western Saudi Arabia, Kordy et al. [24] stated that higher birth order was associated with shorter duration of breastfeeding $(p<0.001)$.

The use of oral contraception was found to have a negative effect on breastfeeding as reported in two papers by Al-Hreashy et al. [26] $(\mathrm{OR}=4.6,95 \% \mathrm{CI}=2.8$ 7.3) and Shawky et al. [31] $(\mathrm{OR}=1.5,95 \% \mathrm{CI}=1.1-2.2$, $p$-value $=0.031)$. Shawky et al. [31] stated that caesarean section as a method of delivery was associated with shorter a duration $(\mathrm{OR}=1.9,95 \% \mathrm{CI}=1.3-2.8, p$-value $=$ 0.001), however, Al-Hreashy et al. [26] found no association $(\mathrm{OR}=0.81,95 \% \mathrm{CI}=0.45-1.43)$.

\section{Reasons for not breastfeeding}

Table 3 lists the reasons given by mothers for not breastfeeding at all or breastfeeding cessation after its establishment. The most common reason was insufficient breast milk' and this reason was reported by about a half of the sample in some studies $[19,32,34]$. The predominance of such a reason was explained by less breast stimulation, and thus, less secretion of milk due to reduced suckling of the breast when introducing bottle feeding [24,32]. Although physiological deficiency does occur, it is probably not the main cause of perceived milk insufficiency $[27,33]$. Also, mothers may simply have believed that breast milk alone is not sufficient for their babies' health [26]. Other reasons include sickness of the mother or child, becoming pregnant, breastfeeding problems, and others. These reasons were given less frequently, but varied considerably in the proportion of mothers across the reviewed papers (Table 3).

\section{Other factors not included in the reviewed studies}

There were several important risk factors that were not included in the reviewed studies. Maternal obesity is a risk factor for not breastfeeding and for a shorter duration of breastfeeding [36,37]. Nevertheless, previous studies in Saudi Arabia have not addressed the association between breastfeeding practices and other important factors such as maternal obesity (51\% among Saudi females in 2007) and Type 2 diabetes (21.4\% among females in 2000) $[38,39]$. Also, factors that are believed to affect breastfeeding such as the type of formulas used, their commercial advertisements, and parental attitudes have not been documented.

\section{Limitations}

This review has several limitations in the data presented on breastfeeding in the KSA. These are mainly related to the paucity of the studies, the small sample sizes and the lack of standard definitions. All studies included in the review are of cross-sectional design and there is a need for more appropriate methods to study breastfeeding,

Table 3 Reasons of not breastfeeding or stopping breastfeeding as reported by reviewed studies

\begin{tabular}{|c|c|c|c|c|c|}
\hline Study & $\begin{array}{l}\text { Insufficient } \\
\text { milk (\%) }\end{array}$ & $\begin{array}{c}\text { Sickness of } \\
\text { mother or child (\%) }\end{array}$ & New pregnancy (\%) & Breastfeeding problems (\%) & Others (\%) \\
\hline 1987, National (Al-Othaimeen 1987 [35]) & 22.97 & 7.4 & 67.7 & - & 1.95 \\
\hline 1987, National (Al-Mazrou 1994 [18]) & 43 & 11 & 4 & 11 & 21 \\
\hline 1991, National (Al-Shehri 1995 [20]) & 45 & 9.5 & 3.5 & 5 & 17.5 \\
\hline 1992, Makkah (West) (Kordy 1992 [24]) & 30.9 & 8.4 & 27.3 & 1.25 & - \\
\hline 1995, Riyadh (Central) (Al-Ayed 1998 [32]) & 52.6 & - & - & - & 27.5 \\
\hline 1999, Riyadh (Central) (Al-Jassir 2004 [19]) & 66.1 & 4.1 & 5.1 & - & 20.6 \\
\hline 2001-02, Jeddah (West) (Fida 2003 [33]) & 50 & 8.2 & 1.8 & 1.8 & 10.9 \\
\hline 2002-03, National (Al-Jassir 2006 [34]) & 48.3 & 11.5 & 13.2 & - & 8.8 \\
\hline 2004-05, National (El Mouzan 2009 [27]) & 45.5 & 30.4 & - & 11.9 & 12.2 \\
\hline 2005, Riyadh (Central) (Al-Hreashy 2008 [26]) & 49.6 & 11.2 & - & 11.6 & 6.6 \\
\hline 2011, Jeddah (West) (Eldeek 2012 [22]) & 32 & 19 & - & - & 3.3 \\
\hline
\end{tabular}


such as cohort designs. Most studies reviewed did not include multivariate analysis and for those that did there was no consistency in the covariates used for adjustment. Furthermore, most studies included lack standard definitions of breastfeeding, and this demonstrates the need for investigations that are based on valid classification criteria.

\section{Conclusion}

Research on breastfeeding in Saudi Arabia to date has been based on cross-sectional study designs and there is a need for cohort studies to more accurately measure breastfeeding and risk factors. The poor study designs and sample selection are reflected in the disparities in reported breastfeeding rates, and particularly in reported 'exclusive breastfeeding' rates. The duration of any breastfeeding showed a decline over time, within the limitations of the samples used. Older, less educated and multiparous mothers who lived in rural communities and belonged to the low socio-economic class were more likely to breastfeed and have prolonged duration compared to other groups. The most common cause of breastfeeding cessation and introduction of alternative feedings was insufficient breast milk; a reason that may be more perceived than real.

It is recommended that breastfeeding patterns and practices in the KSA be re-assessed using a more appropriate research design like cohort studies which can analyse follow up data and present more accurate and valid results. This is necessary to inform the breastfeeding promotion programs in this country. It is hoped that this review will serve as baseline information for any upcoming longitudinal studies on breastfeeding in Saudi Arabia or a part of it.

\section{Competing interests}

The authors declare that they have no competing interests.

\section{Author's contributions}

CB searched the literature, wrote and revised the manuscript. DA searched the literature and wrote the manuscript. RG revised the manuscript. All authors read and approved the final manuscript.

\section{Author details \\ ${ }^{1}$ College of Applied Medical Sciences, Taif University, PO Box 888, Taif 21974, Saudi Arabia. ${ }^{2}$ School of Public Health and Curtin Health Innovation Research Institute, Curtin University, Perth, Western Australia 6845, Australia. ${ }^{3}$ School of Public Health, WA Centre for Health Promotion Research, Curtin University, Perth, Western Australia 6845, Australia.}

Received: 17 January 2013 Accepted: 15 December 2013 Published: 14 January 2014

\section{References}

1. Binns C, Graham K: Project report of the Perth Infant Feeding Study Mark II (2002-2004). Commonwealth Department of Health and Ageing: Canberra; 2005.

2. World Health Organization: Planning guide for national implementation of the Global Strategy for Infant and Young Child Feeding. Geneva: WHO; 2007.
3. James DC, Lessen R: Position of the American Dietetic Association: promoting and supporting breastfeeding. J Am Diet Assoc 2009, 109:1926-1942.

4. Kramer MS, Kakuma R: Optimal duration of exclusive breastfeeding. Cochrane Database Syst Rev 2012, 8, CD003517.

5. World Health Organization: Exclusive breastfeeding for six months best for babies everywhere. 2011. http://www.who.int/mediacentre/news/ statements/2011/breastfeeding_20110115/en/index.html.

6. American Academy of Pediatrics: Breastfeeding and the use of human milk. Pediatrics 2012, 129:e827-e841.

7. Eastern Mediterranean Regional Office of WHO (EMRO): Breastfeeding in the EMRO region 2012. http://www.emro.who.int/health-topics/ breastfeeding/.

8. Dop M-C, Benbouzid D, Trèche S, de Benoist B, Verster A, Delpeuch F: (editors): Complementary feeding of young infants in Africa and the Middle East. Geneva: WHO; 1999.

9. World Health Organization: Global data bank on infant and young child feeding. 2009. http://www.who.int/nutrition/databases/infantfeeding/ countries/en/index.html\#S.

10. Central Department of Statistics and Information in KSA [CDSI]: Annual statistical book. no. 47. Riyadh: CDSl; 2010.

11. Ministry of Health in the Kingdom of Saudi Arabia: The health statistical year book. Riyadh: $\mathrm{MOH} ; 2010$.

12. World Health Organization: World Health Statistics 2012. Geneva: WHO; 2012:141-142.

13. World Health Organization: Saudi Arabia Country profile. Nutrition. 2010. http://apps.who.int/nutrition/landscape/report.aspx?iso=sau.

14. Al-Jassir M, Moizuddin SK, Al-Bashir B: A review of some statistics on breastfeeding in Saudi Arabia. Nutr Health 2003, 17:123-130.

15. Moher D, Liberati A, Tetzlaff J, Altman DG: Preferred reporting items for systematic reviews and meta-analyses: the PRISMA statement. Br Med J 2009, 339:332-336.

16. World Health Organization: Indicators for assessing infant and young child feeding practices - Part 1: definitions. In Conclusions of a consensus meeting held 6-8 November 2007 in Washington D.C., USA. Geneva: WHO Press; 2008.

17. Binns CW, Fraser ML, Lee AH, Scott J: Defining exclusive breastfeeding in Australia. J Paediatr Child Health 2009, 45:174-180.

18. Al-Mazrou YY, Aziz KMS, Khalil M: Breast-feeding and weaning practices in Saudi-Arabia. J Trop Pediatr 1994, 40:267-271.

19. Al-Jassir MS, El-Bashir BM, Moizuddin SK: Surveillance of infant feeding practices in Riyadh city. Ann Saudi Med 2004, 24:136-140.

20. Al-Shehri SN, Farag MK, Baldo MH, Al-Mazrou YY, Aziz KMS: Overview on breastfeeding patterns in Saudi Arabia. J Trop Pediatr 1995, 41:38-44.

21. Amin T, Hablas $H, A l$ Qader AA: Determinants of initiation and exclusivity of breastfeeding in Al Hassa, Saudi Arabia. Breastfeed Med 2011, 6:59-68

22. Eldeek BS, Tayeb SO, Habiballah SB: Knowledge, attitudes and practice of mothers toward breast feeding at Well Baby Clinic, King Abdulaziz University Hospital. J American Sci 2012, 8:157-162.

23. Khattab MS: Cross-sectional study of a child health care programme at one family practice centre in Saudi Arabia. East Mediterr Health J 2000, 6:246-259.

24. Kordy MN, Ibrahim MA, El-Gamal FM, Bahnassy AA: Factors affecting the duration of breastfeeding in a rural population of Saudi Arabia. Asia Pac J Public Health 1992, 6:35-39.

25. National Health and Medical Research Council: How to use the evidence: assessment and application of scientific evidence. Canberra: NHMRC; 2000

26. Al-Hreashy FA, Tamim HM, Al-Baz N, Al-Kharji NH, Al-Amer A, Al-Ajmi H, Eldemerdash AA: Patterns of breastfeeding practice during the first 6 months of life in Saudi Arabia. Saudi Med J 2008, 29:427-431.

27. El Mouzan MI, Al Omar AA, Al Salloum AA, Al Herbish AS, Qurachi MM: Trends in infant nutrition in Saudi Arabia: compliance with WHO recommendations. Ann Saudi Med 2009, 29:20-23.

28. El-Gilany A, Shady E, Helal R: Exclusive breastfeeding in Al-Hassa, Saudi Arabia. Breastfeed Med 2011, 6:209-213.

29. Serenius F, Swailem AR, Edressee AW, Hofvander Y: Patterns of breastfeeding and weaning in Saudi-Arabia. Acta Paediatr Scand Suppl 1988, 346:121-129.

30. Madani KA, Al-Nowaisser AA, Khashoggi RH: Breast feeding patterns in Saudi Arabia. Ecol Food Nutr 1994, 31:239-245. 
31. Shawky S, Abalkhail BA: Maternal factors associated with the duration of breast feeding in Jeddah, Saudi Arabia. Paediatr Perinat Epidemiol 2003, 17:91-96.

32. Al-Ayed IH, Qureshi Ml: Breastfeeding practices in urban Riyadh. J Trop Pediatr 1998, 44:113-117.

33. Fida NM, Al-Aama JY: Pattern of infant feeding at a university hospital in Western Saudi Arabia. Saudi Med J 2003, 24:725-729.

34. Al-Jassir MS, El-Bashir BM, Moizuddin SK, Abu-Nayan AAR: Infant feeding in Saudi Arabia: mothers' attitudes and practices. East Mediterr Health J 2006, 12:6-13.

35. Al-Othaimeen Al, Villanueva BP, Devol EB: The present trend in infant feeding practices in Saudi Arabia. Food Nutr Bull 1987, 9:62-68.

36. Donath SM, Amir LH: Does maternal obesity adversely affect breastfeeding initiation and duration? I Paediatr Child Health 2000, 36:482-486.

37. Li R, Jewell S, Grummer-Strawn L: Maternal obesity and breast-feeding practices. Am J Clin Nutr 2003, 77:931-936.

38. Al-Nozha MM, Al-Maatouq MA, Al-Mazrou YY, Al-Harthi SS, Arafah MR, Khalil MZ, Khan NB, Al-Khadra A, Al-Marzouki K, Nouh MS: Diabetes mellitus in Saudi Arabia. Saudi Med J 2004, 25:1603-1610.

39. Al-Baghli NA, Al-Ghamdi AJ, Al-Turki KA, El-Zubaier AG, Al-Ameer MM, Al-Baghli FA: Overweight and obesity in the eastern province of Saudi Arabia. Saudi Med J 2008, 29:1319-1325.

\section{Submit your next manuscript to BioMed Central and take full advantage of:}

- Convenient online submission

- Thorough peer review

- No space constraints or color figure charges

- Immediate publication on acceptance

- Inclusion in PubMed, CAS, Scopus and Google Scholar

- Research which is freely available for redistribution 